\title{
Evaluating the Capabilities Model of Dementia Care: a non-randomized controlled trial exploring resident quality of life and care staff attitudes and experiences
}

\section{Professor Wendy Moyle *}

Director, Centre for Health Practice Innovation

Centre for Health Practice Innovation, Menzies Health Institute Queensland, School of Nursing \& Midwifery, Griffith University, Nathan, Brisbane, Queensland, 4111, Australia.

Tel: +61 (0) 737355526

Email: w.moyle@griffith.edu.au

\section{Associate Professor Lorraine Venturato}

Chair, Gerontology

Faculty of Nursing, University of Calgary, Calgary T2N 1N4, Canada.

Tel: +1 (403) 2206444

Email: lventura@ucalgary.ca

\section{Professor Marie Cooke}

Deputy Director, Centre for Health Practice Innovation

Centre for Health Practice Innovation, NHMRC Centre of Research Excellence in Nursing, Menzies Health Institute Queensland, School of Nursing \& Midwifery, Griffith University, Nathan, Brisbane, Queensland, 4111, Australia.

Tel: +61 (0) 737355253

Email: $\underline{\text { m.cooke@griffith.edu.au }}$ 


\section{Ms Jenny Murfield}

Research Development Officer

Centre for Health Practice Innovation, Menzies Health Institute Queensland, Griffith University, Nathan, Brisbane, Queensland, 4111, Australia

Tel: +61 (7) 37357855

Email: j.murfield@griffith.edu.au

\section{Ms Susan Griffiths}

Deputy Executive Officer

Executive, Pro Vice Chancellor (Health), Griffith University, Gold Coast Campus, Queensland, Australia

Tel: +61 (7) 56780838

Email: s.griffiths@griffith.edu.au

\section{Professor Julian Hughes}

Honorary Professor of Philosophy of Ageing and Consultant in Old Age Psychiatry

Northumbria Healthcare NHS Foundation Trust and Policy, Ethics and Life Sciences (PEALS) Research Centre, Newcastle University, Newcastle-Upon-Tyne, NE1 7RU, United Kingdom. Tel: +44 (0) 1912934057

Email: julian.hughes@ncl.ac.uk

\section{Mr Nathan Wolf}

Research Assistant

Centre for Health Practice Innovation, Menzies Health Institute Queensland, Griffith University, Nathan, Brisbane, Queensland, 4111, Australia 
Email: natubu@hotmail.com

\section{* Author for correspondence}

Professor Wendy Moyle, Centre for Health Practice Innovation, Menzies Health Institute Queensland, School of Nursing \& Midwifery, Griffith University, 2.10 Health Sciences (N48), 170 Kessels Road, Nathan, Brisbane, Queensland, 4111, Australia.

Tel: +61 (0) 73735 5526; Fax: +61 (0) 7373 55431; Email: w.moyle@griffith.edu.au 


\begin{abstract}
Background: This 12-month, Australian study sought to compare the Capabilities Model of Dementia Care (CMDC) with usual long-term care, in terms of 1) the effectiveness of the CMDC in assisting care staff to improve QOL for older people with dementia; and 2) whether implementation of the CMDC improved staff attitudes towards, and experiences of, working and caring for the person with dementia.
\end{abstract}

Methods: A single blind, non-randomized controlled trial design, involving CMDC intervention group (three facilities) and a comparison usual long-term care practice control group (1 facility), was conducted from August 2010 to September 2011. Eighty-one staff members and 48 family members of a person with dementia were recruited from these four long-term care facilities. At baseline, six-, and 12-months, staff completed a modified Staff Experiences of Working with Demented Residents questionnaire (SEWDR), and families completed the Quality of Life - Alzheimer’s Disease questionnaire (QOL-AD).

Results: Long-term care staff in the usual care group reported significantly lower SEWDR scores (i.e., less work satisfaction) than those in the CMDC intervention group at 12-months $(p=0.005)$. Similarly, family members in the comparison group reported significantly lower levels of perceived QOL for their relative with dementia (QOL-AD scores) than their counterparts in the CMDC intervention group at 12-months $(p=0.012)$.

Conclusions: Although the study has a number of limitations the CMDC appears to be an effective model of dementia care - more so than usual long-term care practice. The CMDC requires further evaluation with participants from a diverse range of LTC facilities and stages of cognitive impairment. 
Key words: Dementia; Long-Term Care; Nursing Care Management; Nursing Models; Quality Of Life; Quantitative Evaluation; Work Satisfaction.

Running title: Evaluating The Capabilities Model of Dementia Care 


\section{Introduction}

Over the last two decades, there has been a growing interest in how to provide the best care for people with dementia to enable them to achieve a quality of life worth living. Currently, however, there are few well-defined models to guide long-term dementia care. Those that are most widely used, such as person-centred care, are not always well understood by care staff, leading to inconsistent implementation and a discrepancy between philosophy and practice (Brooker, 2003; McCormack, 2004; Moyle et al., 2013b; Moyle et al. 2015). The Capabilities Model of Dementia Care (CMDC) was developed in order to directly address this gap, by providing a theoretically driven, yet pragmatically focused framework to guide optimum dementia care practice in long-term care (LTC) facilities.

The CMDC was originally developed and trialled in a mixed-methods study involving four LTC facilities in Australia, and then reviewed by an international expert advisory panel in 2008 (Moyle et al., 2011a; Moyle et al., 2011b; Moyle et al., 2012a; Moyle et al., 2012b; Moyle et al., 2014). The CMDC is underpinned by theoretical principles derived from personcentred, strengths-based, and relationship-centred models of dementia care. The model draws most heavily, however, on the Capabilities Approach. This approach premises that human well-being is a matter of utmost moral importance. Achieving such well-being is borne out of the opportunities available to all individuals to do, and be, what they value, and the type of life they are able to lead. The uniqueness of the CMDC is its incorporation of the list of 10 'central human capabilities' important to all individuals and their well-being (Nussbaum, 2000). Adaptions were made to each capability for specificity to people with dementia, so that they:

1) Feel valued; 2) Experience the best health possible; 3) Live independently with compassionate support from important others; 4) Enjoy pleasurable experiences through senses, imagination and thought; 5) Experience and express emotion in a way that is true to 
oneself; 6) Reflect and decide on things that matter to oneself, including plans for the future and end of life; 7) Experience connection with others where one can contribute, and be contributed to, and where there is self-respect, dignity, and a sense of shared humanity with individuals and the wider community; 8) Live in a way where engaging with nature is a natural part of life; 9) Play in a way that is meaningful and fun for oneself; and 10) Experience a sense of control over how one lives one's life.

The CMDC aims to improve Quality Of Life (QOL) of people with dementia. It also aims to improve the experiences of their family members, and the attitudes and experiences of facility staff caring for, and working with, the person with dementia. In doing so, the model assumes a four-step Capabilities Care Cycle (see Figure 1) in which the 10 central human capabilities are directly linked. The model advocates a proactive and supportive environment, encouraging LTC staff to focus on the strengths and capabilities of the person with dementia rather than their deficits. Specific training and education helps staff to be focused on solutions to meet the needs of the person with dementia better. The innovation of the model is demonstrated in a specifically developed electronic capability care plan that incorporates the 10 central human capabilities. The care plan prompts staff to conduct assessment and evaluation of the person's strengths. Furthermore, the model advocates a staffing model that includes specialised staff skills and adequate staff numbers, to ensure that care is consistently and meaningfully applied. In addition the model advocates a range of practical resources such as tip sheets written for each of the capabilities, to aid implementation of the CDMC. Importantly a key resource is a person dedicated as a capability mentor. This individual is trained as an expert in the CMDC and they oversee staff education and consistency of implementation of the model. The capability mentor also reviews resident care plans with residents, families and staff. 
The study described herein was part of a larger program of research that sought to determine the usability and utility of the CMDC for older people with dementia, their families, and care staff working and caring for the person with dementia in LTC facilities (see Moyle et al., 2013b; Cooke et al., 2014). This paper is specifically focussed on the outcomes of a 12month comparative evaluation of the CMDC with LTC facility usual practice.

\section{Methods}

\section{Aim}

The current study aimed to assess 1) the effectiveness of the CMDC in assisting LTC staff to improve QOL for older people with dementia living in LTC facilities; and 2) whether implementation of the CMDC improved staff attitudes towards, and experiences of, working and caring for the person with dementia.

\section{Design}

The study employed a single blind, non-randomized controlled trial design, involving a CMDC intervention group (three facilities) and a comparison usual care group (1 facility), to implement and evaluate the CMDC from August 2010 to September 2011. The University’s Human Research Ethics Committee granted ethical approval for the study, and the aged care partner organisation formally endorsed the research.

\section{Setting}


Four, mixed-sex LTC facilities, managed and owned by one not-for-profit aged care organisation located in South East Queensland (Australia), were recruited for the study. Final selection of the sites was based on proximity to the University, commitment of management and staff to the project objectives, and similarity of organisational characteristics. In an effort to balance participant numbers, LTC facilities were assigned to intervention or comparison groups based on the number of resident-family dyads available to participate in other aspects of this study, as reported elsewhere (Moyle et al., 2013b; Cooke et al., 2014). All four facilities provided both low (assisted living) and high (nursing home) care, were medium-sized (bed numbers ranged from 60 to 164) and considered representative of Australian LTC facilities.

\section{Sample}

Non-random, purposive sampling was used to recruit as many facility staff and family members of a person with dementia as possible, from the four LTC facilities. All participants were required to be proficient in both written and spoken English. Specific inclusion criteria were that staff members worked at the respective facility for at least two months as either a Personal Care Worker, Diversional Therapist, or Registered Nurse (RN), and that family members visited the LTC facility at least once a month to see their older relative. The older relative either had a i) confirmed diagnosis of dementia, ii) score of 18 to 27 on the Mini Mental State Examination (Folstein et al., 1975), or iii) a score of $\geq 3$ on the Psychogeriatric Assessment Scales - Cognitive Impairment Scale (Jorm et al., 1995)).

\section{Intervention and usual care control groups}


Two RNs, both employed by the University for 21 hours per week and trained by the research team, provided on-site group and individualised education and mentorship in the use of the CMDC to staff at the three intervention facilities over a period of eight months. The face to face didactic education component, which family members could also (and did) attend, involved a total of 12 hours of small group education focused on the CMDC, care planning, review of current practice, and dementia (see Table 1). Six members of the care staff, two from each intervention facility, received additional training by the study RNs and three members of the research team, to equip them as capability mentors in the final four months of the trial. The aim was to improve the sustainability of the CMDC approach beyond the study period. Additional education sessions were conducted with these staff members, which focused on the CMDC, the role of the mentor, and being a leader.

The comparison usual care facility received a single session of 4 hours of education in person-centred care. This was conducted by a member of the research team at the start of the trial.

\section{Data collection}

Data collection using two outcome measures occurred at three time-points during the study: baseline; six-; and 12-months:

\section{STAFF EXPERIENCE OF WORKING WITH DEMENTED RESIDENTS} QUESTIONNAIRE (SEWDR) (originally developed by Astrom et al., 1991; modified for use in an Australian context by Moyle et al., 2011a): Facility staff self-completed this 21-item questionnaire that assesses staff experiences and satisfaction, and their relationship with other staff and relatives of people living with dementia. Statements are scored on a scale from ' $0=$ 
not at all' to ' $4=$ extremely', with a total score and six possible sub-scores being calculated (satisfaction with: ‘feedback’; ‘care organisation’; ‘one’s own expectations’; 'patient contact’; 'expectations of others'; and 'the environment'). Higher scores are indicative of greater staff satisfaction. When modified for use in an Australian context, by way of more culturally appropriate wording (i.e., 'patient' changed to 'resident'), the measure shows adequate reliability ( $\alpha=.80$; pre-intervention $\alpha=.93$ and post-intervention $\alpha=.87$ ) (Moyle et al., 2011a; Moyle et al., 2013a respectively). This is supported in the current study with good reliability demonstrated at all three time-points: baseline $(\alpha=.85)$, six-months $(\alpha=.87)$, and 12-months $(\alpha=.89)$.

2. QUALITY OF LIFE - ALZHEIMER'S DISEASE (QOL-AD) (originally developed by Logsdon et al., 1999; Logsdon et al., 2002; modified for use in LTC by Edelman et al., 2005): Family members completed this 15-item measure in an interview-led discussion with trained RAs employed by the University. Statements relating to physical health, energy, mood, and memory are scored on a scale from ' $1=$ poor' to ' $4=$ excellent', and a single total score is calculated. These scores can range from 15 - 60, with higher scores indicating greater QOL. When used in an Australian context, the measure has shown good levels of reliability $(\alpha=.86$, and $\alpha=.89$ ) (Moyle et al., 2012a; Moyle et al., 2012b respectively). This is supported by the study described here, with reliability ranging from $\alpha=.83$ at baseline, to $\alpha=.90$ at six-months, and $\alpha=.89$ at 12 -months.

In addition to these outcome measures, trained RAs also collected a range of demographic information from all participating facility care staff and family members at baseline (see Tables 2 and 3). Further, information relating to the resident's level of cognitive functioning was also obtained, with trained RAs assessing residents on the MMSE at baseline (Folstein et al., 1975). Trained facility care staff assessed residents on the Psychogeriatric 
Assessment Scales - Cognitive Impairment Scale (PAS-CIS) (Jorm et al., 1995) at baseline and 12-months.

\section{Data analysis}

All data were entered and analysed using the IBM Statistical Package for the Social Sciences Version 19.0 (SPSS Inc., Chicago, IL, USA). Basic frequencies were initially run to screen for missing values and outliers, and to determine accuracy of data entry. Following missing values analyses, which indicated all data to be missing at random, an intention to treat (ITT) framework was assumed (81 staff members; 48 family members). Mean scores were calculated for values missing at baseline, and a 'last-observation carried forward' method was used to impute missing values at six- and 12-months. By means of sensitivity analyses, parallel analyses were undertaken on the imputed ITT data set and the original data set with missing values. No differences were observed and, thus, the reported $p$ values are from the ITT data set.

Total mean scores were computed for the SEWDR and the QOL-AD, with cronbach's coefficient alphas $(\alpha)$ calculated for both measures to verify internal consistency. Basic frequencies were run for all care staff and family member demographics, and a series of Kolmogorov-Smirnov tests were used to check normality of distributions. To determine any differences and/or changes in cognitive impairment (PAS-CSI) between residents in the intervention and comparison groups at baseline and 12-months, a repeated measures ANOVA, with Bonferroni pairwise comparisons, was undertaken. Specifically, a group by time ANOVA was employed to assess changes in mean PAS-CIS scores from baseline to 12-months. 
To assess how the CMDC intervention may have affected staff experiences of working with and caring for older people with dementia (SEWDR), and family member's perceptions of their relative's QOL (QOL-AD), two separate repeated measures ANOVAs, with Bonferroni pairwise comparisons, were undertaken. Specifically: a group by care staff position by time ANOVA was employed to assess changes in mean SEWDR total scores between groups across the three time-points; and a group by time ANOVA was employed to assess changes in mean QOL-AD total scores from baseline, to six-, and 12-months.

To explore the potential influence of intervention facility level effects, a series of oneway ANOVAs were undertaken. Specifically, separate ANOVAs were employed to assess the following mean scores between the three intervention facilities: MMSE (at baseline); PAS-CSI (at baseline and 12-months); SEWDR (at baseline, six- and 12-months); and QOL-AD (at baseline, six- and 12-months).

All statistics are reported at a significance level of 0.05, and the Greenhouse Geisser $p$ value is given where sphericity was not assumed.

\section{Results}

A total of 81 LTC facility staff members (51 from the three intervention facilities and 30 from the comparison group) and 48 family members (37 from the three intervention facilities and 11 from the comparison group) were recruited. Tables 2 and 3 provide details of the demographic characteristics of the two participant groups.

[INSERT TABLES 2 \& 3] 
Residents in the intervention and usual care groups were similar in terms of their level of cognitive impairment at baseline, with PAS-CIS mean scores indicating mild impairment (8.97 and 7.73 respectively), and MMSE mean scores indicating middle-stage dementia (17.97 and 18.73 respectively). When assessed on the PAS-CIS at 12-months, residents' levels of cognitive impairment remained similar (10.96 and 12.10 respectively). However, both groups experienced significant cognitive decline from baseline, worsening from mild to moderate cognitive impairment $(F(1,34)=13.943, p=0.001)$ (see Table 4$)$. There were no significant differences in the mean PAS-CIS scores between the three intervention facilities at baseline $(F(2,34)=0.006, \mathrm{p}=0.994)$ or 12 -months $(F(2,26)=0.195, \mathrm{p}=0.824)$, or baseline mean MMSE scores $(F(2,35)=1.818, \mathrm{p}=0.178)$.

[INSERT TABLE 4]

\section{Staff experiences of working with and caring for older people with dementia}

There was a significant group by time interaction for the $\operatorname{SEWDR}(F(2,136)=4.206, p=$ 0.017), with pairwise comparisons revealing significant differences between the intervention and usual care group occurring at the 12-month time-point $(F(1,68)=8.416, p=0.005)$. Specifically, inspection of means showed that staff in the usual care group reported lower SEWDR scores (i.e., less work satisfaction) than their intervention group counterparts (2.51 versus 2.71 respectively). This difference is likely driven by a significant decrease in mean SEWDR comparison group scores from baseline to 12 months ( $p=0.013 ; 2.69$ to 2.51 ) (see Table 5). There were no significant differences in the mean SEWDR scores between the three intervention facilities at baseline $(F(28,50)=1.047, \mathrm{p}=0.462)$, six-months $(F(27,50)=1.124$, $\mathrm{p}=0.391)$, or 12-months $(F(35,50)=1.970, \mathrm{p}=0.080)$. 
[INSERT TABLE 5]

\section{Family members perceptions of the older person with dementia's Quality of Life}

There was a significant group by time interaction for the QOL-AD $(F(2,92)=3.985, p=0.022)$, with pairwise comparisons revealing significant differences between the intervention and usual care groups occurring at 12 -months $(F(1,46)=6.851, p=0.012)$, and also nearing statistical significance at six-months $(F(1,46)=3.942, p=0.053)$. Specifically, at both six- and 12 -months, family members in the comparison group reported lower levels of perceived QOL for their relative with dementia than family members in the intervention group (6-months: 1.87 versus 2.18; 12 -months: 1.75 versus 2.12 respectively). This difference is, again, likely driven by a significant decrease in mean QOL-AD comparison group scores from baseline to 12 months ( $p=0.018 ; 2.01$ to 1.75 ) (see Table 6 ). There were no significant differences in the mean QOL$\mathrm{AD}$ scores between the three intervention facilities at baseline $(F(2,36)=1.463, \mathrm{p}=0.246)$, sixmonths $(F(2,36)=0.298, \mathrm{p}=0.744)$, and 12-months $(F(2,36)=0.321, \mathrm{p}=0.728)$.

[INSERT TABLE 6]

\section{Discussion}

The results of this 12-month implementation study suggest that the CMDC appears to be an effective model of dementia care - and more so than usual long-term care. The model appears to assist care staff to improve QOL for older people with dementia, and improve care staff attitudes towards, and experiences of, working and caring for the person with dementia. Specifically, the study found that staff in the usual care group reported significantly lower 
levels of work satisfaction than those in the CMDC group at 12-months; and that family members in the comparison group reported significantly lower levels of perceived QOL for their relative than their CMDC counterparts at 12-months. Such positive changes after implementation of the CMDC are consistent with qualitative findings from our larger program of research determining the usability and utility of the CMDC (Moyle et al., 2013b).

In terms of clinical implications, the results from the current study and the complementary qualitative evaluation (Moyle et al., 2013b) highlight how, in order for improvements in long-term dementia care to be made, both philosophical and clinical practice changes must occur. In particular, individualised care, which values the person with dementia's life experience, and interpersonal interactions, which support them to set their own life and care directions, are essential for QOL (Vernooij-Dassen et al., 2010; Moyle et al., 2014). Indeed, this study supports a person-centred focus in all aspects of long-term care practice.

Although many practitioners understand the importance of care that involves clients in decision-making this is often not achieved owing to a biomedical model focusing on the disease, and misunderstanding surrounding dementia that results in a lack of recognition of the person's agency (Boyle 2014). Where agency is ignored the person is considered to have little to contribute to their care or life decisions. The CMDC recognises a person's agency and the means for this to flourish while supporting the notion that negative emotion and behaviour can occur as a result of a lack of agency rather than solely as a focus of the disease.

There are a number of challenges to the implementation of person-centred care (Kirkley et al. 2011), and while there are many examples of good practice the challenges are often around sustainability and staff interpretations of person-centred care, and therefore practice (Chenoweth et al. 2014, Clissett et al. 2013). The question must then be asked why this study successfully influenced change in the intervention facilities and appears to have sustained the 
change over a 12-month period? It is assumed that this is related to the grounding of the CMDC in a strong philosophical (Nussbaum, 2000) and educational framework (Cooke et al. 2014), and clinical mentors (part-time for 8-months) to support and train staff and to maintain sustainability of the CMDC. These elements help to improve staff attitudes and capacity to understand and work directly with people with dementia, families and other care staff. Furthermore organisational support in using a CMDC electronic care plan developed for the model enabled staff to maintain a focus on the person and their 10 capabilities.

Previous research has shown that care staff who are more person-centred in their approach have more positive attitudes to the person with dementia and have greater levels of work satisfaction (Zimmerman et al., 2005; Edvardsson et al., 2011; Moyle et al., 2011a). Furthermore, greater job satisfaction is related to better care (Robertson et al., 1995). As such, care staff need support and training from organisational management to create cultural change and ensure such person-centred practice is the norm within the facility (Edvardsson et al., 2009; McCormack et al., 2010). In doing so, staff should be given opportunities to reflect on their practice, particularly as regards to workload and time management, and staff and team relationships (McCormack et al., 2010). Further, support should be afforded to staff to build relationships between themselves and family members, so as to aid the design of more individualised care for the person with dementia. This will also reduce potential tensions between staff and family members, and improve the LTC experience for both (Pashby et al., 2009; Bramble et al., 2011; Moyle et al., 2013b; Moyle et al., 2014). Issues such as the very task-focussed, time-pressured nature of dementia care, and the historically difficult recruitment and retention of LTC staff will, undoubtedly, add to the challenge of creating such cultural change. However, the findings from this 12-month trial demonstrate that alteration in care practice can potentially improve staff satisfaction and client QOL. The findings give heart to how a new model of care can be successfully instituted in LTC facilities, and how positive 
benefits can be seen, not only for the person with dementia, but also for their caregivers and family members. The CMDC offers an evidence-based approach that promotes individual capabilities. As individuals become frailer and cognitive impairment advances, staff using the CMDC approach continue to honour personhood, and importantly, a person's strengths rather than deficits. However, as found in previous studies when attempting to introduce personcentred care (Chenoweth et al. 2014), any attempt to introduce the CMDC into further care settings will only be successful where there is management support and adequate staffing levels.

When interpreting the findings from this study, there are a number of limitations that should be considered. First, the wider generalizability of our results is limited by the relatively small sample of care staff and family members, all of whom were recruited purposively and non-randomly from four LTC facilities owned and operated by one aged care partner organisation in Brisbane (Australia). In addition, the population sampled might not be representative of all LTC populations, as the study was originally focused on people with early to moderate stage dementia. This was considered necessary to reduce the chances of missing data where the participant was unable to complete surveys or interviews. However, overtime missing data became more of as problem as data was missing as a result of progressive cognitive impairment or they died. Secondly, whilst our previous work has demonstrated that people with dementia are able to give assessments of their own QOL (Moyle et al., 2012b), this study only assessed the person with dementia's QOL via proxy accounts (family member). This may have impacted on actual QOL measurement because unless family members spent a reasonable amount of time with their family member they might not have an appropriate appreciation of QOL for the resident. Any future evaluations of the CMDC would benefit from the inclusion of both self-report and proxy accounts of QOL, particularly given there are often discrepancies between the two ratings (with the person with dementia the more positive), thus 
suggesting a potential difference in perspective and evaluation of QOL (Moyle et al., 2012b). Thirdly, whilst our findings suggest a positive effect of the CMDC in comparison to the usual care group, we are careful not to claim causality, as the study did not measure or explore the effect of possible covariates over the course of the 12-months. Personal and clinical characteristics of participating care staff and also family members may have contributed to the observed differences between the intervention/control groups (such as depression, feelings of burden, their own QOL and health, etc.), as also may have been reflected in the profile of the residents with dementia. Nevertheless, residents’ level and trajectory of cognitive impairments between the intervention and usual care groups were similar, and there were no known changes at the organisational level of each facility over the study period that could have influenced ratings (such as new management, change in working conditions, etc.). Finally, there was a loss of participants over time and this may have influenced the findings. However, in any lengthy study that includes participants with dementia, this is likely to be the case due to progression of disease and also death.

Overall, the results from this 12-month comparative evaluation suggest that the CMDC appears to be an effective evidence-based model of LTC facility dementia care, which can successfully contribute to improvements in QOL for people with dementia, and the development of more positive attitudes and work experiences of long-term care facility staff. Further implementation and evaluative research is now needed, with larger numbers of participants from a more diverse range of LTC facilities as well as cognitive impairment, to assess the utility and efficacy of the CMDC more extensively. This will also allow an exploration of the wider generalizability of these initial, promising findings. 


\section{Conflict of interest}

None.

\section{Description of authors' roles}

Wendy Moyle conceived and designed the study, in consultation and review with Marie Cooke, Lorraine Venturato, Susan Griffiths and Julian Hughes. Wendy Moyle, Marie Cooke and Lorraine Venturato oversaw the conduct of the trial at the LTC facilities, and contributed to the collection, analysis and interpretation of data. Wendy Moyle prepared a draft manuscript, and all authors provided comment/revision and approval of the final version.

\section{Acknowledgements}

This study was funded by a Wicking Trust research grant in 2009. The authors thank the International Advisory Panel for their feedback on the CMDC. Thanks are also expressed to RSL Care management for their support and contributions, all staff, family members and residents who took part in the research at the four long-term care facilities. Thanks are also addressed to members of the project team, including Jo Kinnane and Caroline Walters for clinical mentorship. 


\section{References}

Astrom, S., Nilsson, M., Norberg, A., Sandman, P. O. and Winblad, B. (1991). Staff burnout in dementia care - relations to empathy and attitudes. International Journal of Nursing Studies, 28, 65-75.

Boyle, G. (2014). Recognising the agency of people with dementia. Disability \& Society, 29, $1130-1144$.

Bramble, M., Moyle, W. and Shum, D. (2011). A quasi-experimental design trial exploring the effect of a partnership intervention on family and staff well-being in long-term dementia care. Aging Ment Health, 15, 995-1007. doi: 10.1080/13607863.2011.583625.

Brooker, D. (2003). What is person-centred care in dementia? Reviews in Clinical Gerontology, 13, 215-222. doi: 10.1017/S095925980400108X.

Chenoweth, L., Forbes, I., Fleming, R., King, MT., Stein-Parbury, J., Luscombe, G., Kenny, P., Jeon, Y-H., Haas, M., Brodaty, H. (2014). PerCEN: a cluster ranomized controlled trial of person-centred residential care and environment for people with dementia. Int Psychogeriatrics, 26, 1147-1160.

Cooke, M., Moyle, W., Venturato, L., Walters, C. and Kinnane, J. (2014). Evaluation of an education intervention to implement a capability model of dementia care. Dementia The International Journal of Social Research and Practice 13, 613-625. doi: $10.1177 / 1471301213480$

Clissett, P., Porock, D., Harwood, RH., Gladman JRF. (2013). The challenges of achieving person-centred care in acute hospitals: a qualitative study of people with dementia and their families. Int J Nursing Studies, 50, 1495-1503. 
Edelman, P., Fulton, B. R., Kuhn, D. and Chang, C. H. (2005). A comparison of three methods of measuring dementia-specific quality of life: perspectives of residents, staff, and observers. The Gerontologist, 45 Spec No 1, 27-36. doi: 10.1093/geront/45.suppl_1.27.

Edvardsson, D., Fetherstonhaugh, D., McAuliffe, L., Nay, R. and Chenco, C. (2011). Job satisfaction amongst aged care staff: exploring the influence of person-centered care provision. Int Psychogeriatr, 23, 1205-1212. 10.1017/s1041610211000159.

Edvardsson, D., Sandman, P. O., Nay, R. and Karlsson, S. (2009). Predictors of job strain in residential dementia care nursing staff. J Nurs Manag, 17, 59-65. 10.1111/j.13652834.2008.00891.x.

Folstein, M. F., Folstein, S. E. and McHugh, P. R. (1975). "Mini-mental state". A practical method for grading the cognitive state of patients for the clinician. Journal of Psychiatric Research, 12, 189-198.

Jorm, A. F., Mackinnon, A. J., Henderson, A. S., Scott, R., Christensen, H., Korten, A. E., Cullen, J. S. and Mulligan, R. (1995). The Psychogeriatric Assessment Scales: a multidimensional alternative to categorical diagnoses of dementia and depression in the elderly. Psychological Medicine, 25, 447-460.

Kirkley, C., Bamford,C., Poole, M., Arksey, H., Hughes, J., \& Bond, J. (2011). the imapact of organisational culture on the delivery of person-centred care in services providing respite care and short breaks for people with dementia. Health and Social Care in the Community, 19, 438-448.

Logsdon, R., Gibbons, L., McCurry, S. and Teri, L. (1999). Quality of life in Alzheimer's disease: patient and caregiver reports. Journal of Mental Health and Aging, 5, 21-32.

Logsdon, R., Gibbons, L., McCurry, S. and Teri, L. (2002). Assessing quality of life in older adults with cognitive impairment. Psychosomatic Medicine, 64, 510-519. doi: 10.1097/00006842-200205000-00016. 
McCormack, B. (2004). Person-centredness in gerontological nursing: an overview of the literature. Journal of Clinical Nursing, 13, 31-38. doi: 10.1111/j.1365-2702.2004.00924.x. McCormack, B., Dewing, J., Breslin, L., Coyne-Nevin, A., Kennedy, K., Manning, M., Peelo-Kilroe, L., Tobin, C. and Slater, P. (2010). Developing person-centred practice: nursing outcomes arising from changes to the care environment in residential settings for older people. Int J Older People Nurs, 5, 93-107. 10.1111/j.1748-3743.2010.00216.x. Moyle, W., Cooke, M., O'Dwyer, S. T., Murfield, J., Johnston, A. and Sung, B. (2013a). The effect of foot massage on long-term care staff working with older people with dementia: a pilot, parallel group, randomized controlled trial. BMC Nursing, 12, 5. doi: 10.1186/14726955-12-5.

Moyle, W., Gracia, N., Murfield, J. E., Griffiths, S. G. and Venturato, L. (2012a). Assessing quality of life of older people with dementia in long-term care: a comparison of two self-report measures. Journal of Clinical Nursing, 21, 1632-1640. doi: 10.1111/j.13652702.2011.03688.x.

Moyle, W., Murfield, J., Venturto, L., Griffiths, S., Grimbeek, P., McAllister, M. and Marshall, J. (2014). Dementia and its influence on quality of life and what it means to be valued: family members' perceptions. Dementia (London), 13, 412-425. doi: $10.1177 / 1471301212474147$.

Moyle, W., Murfield, J. E., Griffiths, S. G. and Venturato, L. (2011a). Care staff attitudes and experiences of working with older people with dementia. Australasian Journal on Ageing, 30, 186-190. doi: 10.1111/j.1741-6612.2010.00470.x.

Moyle, W., Murfield, J. E., Griffiths, S. G. and Venturato, L. (2012b). Assessing quality of life of older people with dementia: a comparison of quantitative self-report and proxy accounts. Journal of Advanced Nursing, 68, 2237-2246. doi: 10.1111/j.13652648.2011.05912.x. 
Moyle, W., Venturato, L., Cooke, M., Hughes, J., van Wyk, S. and Marshall, J. (2013b). Promoting value in dementia care: staff, resident and family experience of the capabilities model of dementia care. Aging \& Mental Health, 17, 587-594. doi: 10.1080/13607863.2012.758233.

Moyle, W., Venturto, L., Griffiths, S., Grimbeek, P., McAllister, M., Oxlade, D. and Murfield, J. (2011b). Factors influencing quality of life for people with dementia: a qualitative perspective. Aging \& Mental Health, 15, 970-977. doi: 10.1080/13607863.2011.583620.

Moyle, W., Fetherstonhaugh, D., Greben, M., Beattie, E., and the AusQoL group. Influencers on quality of life as reported by people living with dementia in long-term care: a descriptive exploratory approach. BMC Geriatrics, 15:50, DOI 10.1186/s12877-015-0050-z Nussbaum, M. C. (2000). Women and Human Development: The Capabilities Approach. New York: Cambridge University Press.

Pashby, P., Hann, J. and Sunico, M. E. (2009). Dementia care planning: Shared experience and collaboration. Journal of Gerontological Social Work, 52, 837-848. doi: 10.1080/01634370903088051.

Robertson, A., Gilloran, A., McGlew, T., McKee, K., McKinley, A. and Wight, D. (1995). Nurses' job satisfaction and the quality of care received by patients in psychogeriatric wards. International Journal of Geriatric Psychiatry, 10, 575-584. doi: 10.1002/gps.930100708.

Vernooij-Dassen, M., Vasse, E., Zuidema, S., Cohen-Mansfield, J. and Moyle, W. (2010). Psychosocial interventions for dementia patients in long-term care. Int Psychogeriatr, 22, 1121-1128. 10.1017/s1041610210001365. 
Zimmerman, S., Williams, C. S., Reed, P. S., Boustani, M., Preisser, J. S., Heck, E. and Sloane, P. D. (2005). Attitudes, stress, and satisfaction of staff who care for residents with dementia. Gerontologist, 45 Spec No 1, 96-105. 
Table 1. Overview of CMDC Education

\begin{tabular}{cl}
\hline WEEK & \multicolumn{1}{c}{ CONTENT } \\
\hline 1 & Dementia, Values and Personhood \\
2 & Capabilities Mode of Dementia Care: Care Cycle, Strengths and \\
& Relationship Centred Care \\
& Capabilities: Feeling Valued \& Play \\
& Communication. The Care Cycle - Planning Opportunities \\
3 & Capabilities: Emotions \& Senses, Imagination \& Thought \\
& The Care Cycle - Facilitating Care Needs \\
4 & Capabilities: Optimal Health \& Sense of Control \\
& Morals, Reflective Practice \\
5 & Capabilities: Case Review \& Evaluation \\
& Mentor’s Role \\
& Capabilities: Connection \& Contribution \& Natural World
\end{tabular}


Table 2. Care staff member characteristics

\begin{tabular}{|c|c|c|c|}
\hline CHARACTERISTIC & SUB-CATEGORY & $N=$ & $\%$ \\
\hline \multirow[t]{2}{*}{ Sex $(n=81)$} & Female & 75 & 92.6 \\
\hline & Male & 6 & 7.4 \\
\hline \multirow{7}{*}{ Age $(n=74)$} & Under 35 years & 12 & 14.8 \\
\hline & $36-45$ years & 18 & 22.2 \\
\hline & $46-50$ years & 16 & 19.8 \\
\hline & 51-55 years & 14 & 17.3 \\
\hline & $56-60$ years & 10 & 12.3 \\
\hline & 61-65 years & 2 & 2.5 \\
\hline & Over 65 years & 2 & 2.5 \\
\hline \multirow[t]{7}{*}{ Employment position $(n=81)$} & PCW & 34 & 42.0 \\
\hline & APCW & 8 & 9.9 \\
\hline & Diversional Therapist & 9 & 11.1 \\
\hline & EN / EEN & 13 & 16.0 \\
\hline & $\mathrm{RN}$ & 9 & 11.1 \\
\hline & Care Manager & 6 & 7.4 \\
\hline & Lifestyle Manager & 2 & 2.5 \\
\hline \multirow{3}{*}{ Employment status $(\mathrm{n}=81)$} & Part-time & 55 & 67.9 \\
\hline & Full-time & 23 & 28.4 \\
\hline & Casual & 3 & 3.7 \\
\hline \multirow[t]{8}{*}{ Level of education $(n=74)$} & Certificate III & 28 & 34.6 \\
\hline & Certificate IV & 8 & 9.9 \\
\hline & Diploma & 22 & 27.2 \\
\hline & Bachelor & 7 & 8.6 \\
\hline & Masters & 2 & 2.5 \\
\hline & Hospital trained & 5 & 6.2 \\
\hline & Graduate Diploma & 1 & 1.2 \\
\hline & Year 10 & 1 & 1.2 \\
\hline \multirow[t]{4}{*}{ Facility $(\mathrm{n}=81)$} & Intervention 1 & 18 & 22.2 \\
\hline & Intervention 2 & 16 & 19.8 \\
\hline & Intervention 3 & 17 & 21.0 \\
\hline & Comparison & 30 & 37.0 \\
\hline
\end{tabular}

Note. PCW = Personal Care Worker; APCW = Advanced Personal Care Worker; EN = Enrolled Nurse; EEN = Endorsed Enrolled Nurse; RN = Registered Nurse

Some columns may not add up to 100 due to missing data. 
Table 3. Family member characteristics

\begin{tabular}{|c|c|c|c|}
\hline CHARACTERISTIC & SUB-CATEGORY & $N=$ & $\%$ \\
\hline \multirow[t]{2}{*}{ Sex $(n=36)$} & Female & 24 & 50.0 \\
\hline & Male & 12 & 25.0 \\
\hline \multirow[t]{5}{*}{ Age $(n=36)$} & 40-49 years & 2 & 4.2 \\
\hline & 50-59 years & 16 & 33.3 \\
\hline & $60-69$ years & 12 & 25.0 \\
\hline & $70-79$ years & 2 & 4.2 \\
\hline & 80-89 years & 4 & 8.3 \\
\hline \multirow[t]{8}{*}{ Relationship (n=36) } & Daughter & 20 & 41.7 \\
\hline & Son & 7 & 14.6 \\
\hline & Wife & 2 & 4.2 \\
\hline & Husband & 3 & 6.3 \\
\hline & Nephew & 1 & 2.1 \\
\hline & Brother & 1 & 2.1 \\
\hline & Sister & 1 & 2.1 \\
\hline & Daughter-in-law & 1 & 2.1 \\
\hline \multirow[t]{4}{*}{ Employment status $(n=36)$} & Retired & 21 & 43.8 \\
\hline & Part-time & 6 & 12.5 \\
\hline & Full-time & 8 & 16.7 \\
\hline & Casual & 1 & 2.1 \\
\hline \multirow[t]{6}{*}{ Level of education $(n=36)$} & Primary & 7 & 14.6 \\
\hline & Year 10 & 14 & 29.2 \\
\hline & Year 12 & 2 & 4.2 \\
\hline & TAFE & 9 & 18.8 \\
\hline & Bachelor & 3 & 6.3 \\
\hline & Postgraduate & 1 & 2.1 \\
\hline \multirow{7}{*}{ Visiting frequency $(n=36)$} & $<1$ per fortnight & 2 & 4.2 \\
\hline & Once per fortnight & 3 & 6.3 \\
\hline & Twice per fortnight & 3 & 6.3 \\
\hline & 3-6 times per fortnight & 13 & 27.1 \\
\hline & 7-10 times per fortnight & 5 & 10.4 \\
\hline & 11-13 times per fortnight & 3 & 6.3 \\
\hline & Everyday & 7 & 14.6 \\
\hline \multirow{2}{*}{$\begin{array}{l}\text { Provided care for their relative } \\
\text { at home }(\mathrm{n}=36)\end{array}$} & Yes & 18 & 37.5 \\
\hline & No & 18 & 37.5 \\
\hline
\end{tabular}

Note. Some columns may not add up to 100 due to missing data. 
Table 4. Resident PAS-CIS mean scores and standard deviations at baseline and 12-months, and MMSE mean scores and standard deviations at baseline

\begin{tabular}{lcccccc}
\hline GROUP & \multicolumn{3}{c}{ BASELINE } & \multicolumn{3}{c}{ 12 MONTHS } \\
\cline { 2 - 7 } & $N=$ & MEAN & SD & $N=$ & MEAN & SD \\
\hline PAS-CI Intervention & 35 & 8.97 & 4.37 & 27 & 10.96 & 5.33 \\
PAS-CI Usual care & 11 & 7.73 & 3.23 & 10 & 12.10 & 3.67 \\
PAS-CI Total & 46 & 8.67 & 4.13 & 37 & 11.27 & 4.92 \\
MMSE Intervention & 36 & 17.97 & 6.79 & - & - & - \\
MMSE Usual care & 11 & 18.73 & 6.99 & - & - & - \\
MMSE Total & 47 & 18.15 & 6.77 & - & - & - \\
\hline
\end{tabular}

Note: $\mathrm{SD}$ = Standard deviation; PAS-CIS = Psychogeriatric Assessment Scale - Cognitive Impairment Scale; MMSE = Mini Mental State Examination. 
Table 5. Staff SEWDR mean scores and standard deviations at baseline, six-, and 12-months

\begin{tabular}{lcccccc}
\hline \multirow{2}{*}{ GROUP } & \multicolumn{2}{c}{ BASELINE } & \multicolumn{2}{c}{ 6-MONTHS } & \multicolumn{2}{c}{ 12-MONTHS } \\
\cline { 2 - 7 } & MEAN & SD & MEAN & SD & MEAN & SD \\
\hline CMDC Intervention & 2.65 & .45 & 2.69 & .44 & 2.71 & .47 \\
Comparison & 2.69 & .33 & 2.61 & .41 & 2.51 & .37 \\
\hline
\end{tabular}

Note. SEWDR = Staff experiences of working with demented residents questionnaire; SD = Standard deviation; CMDC = Capabilities Model of Dementia Care. 
Table 6. Family QOL-AD mean scores and standard deviations at baseline, six- and 12months

\begin{tabular}{lcccccc}
\hline \multirow{2}{*}{ GROUP } & \multicolumn{2}{c}{ BASELINE } & \multicolumn{2}{c}{6 MONTHS } & \multicolumn{2}{c}{12 MONTHS } \\
\cline { 2 - 7 } & MEAN & SD & MEAN & SD & MEAN & SD \\
\hline CMDC Intervention & 2.13 & .44 & 2.18 & .47 & 2.12 & .43 \\
Comparison & 2.01 & .34 & 1.87 & .45 & 1.75 & .35 \\
\hline Note. QOL-AD = Quality of life - Alzheimer's Disease questionnaire; SD = Standard \\
deviation; CMDC = Capabilities Model of Dementia Care.
\end{tabular}




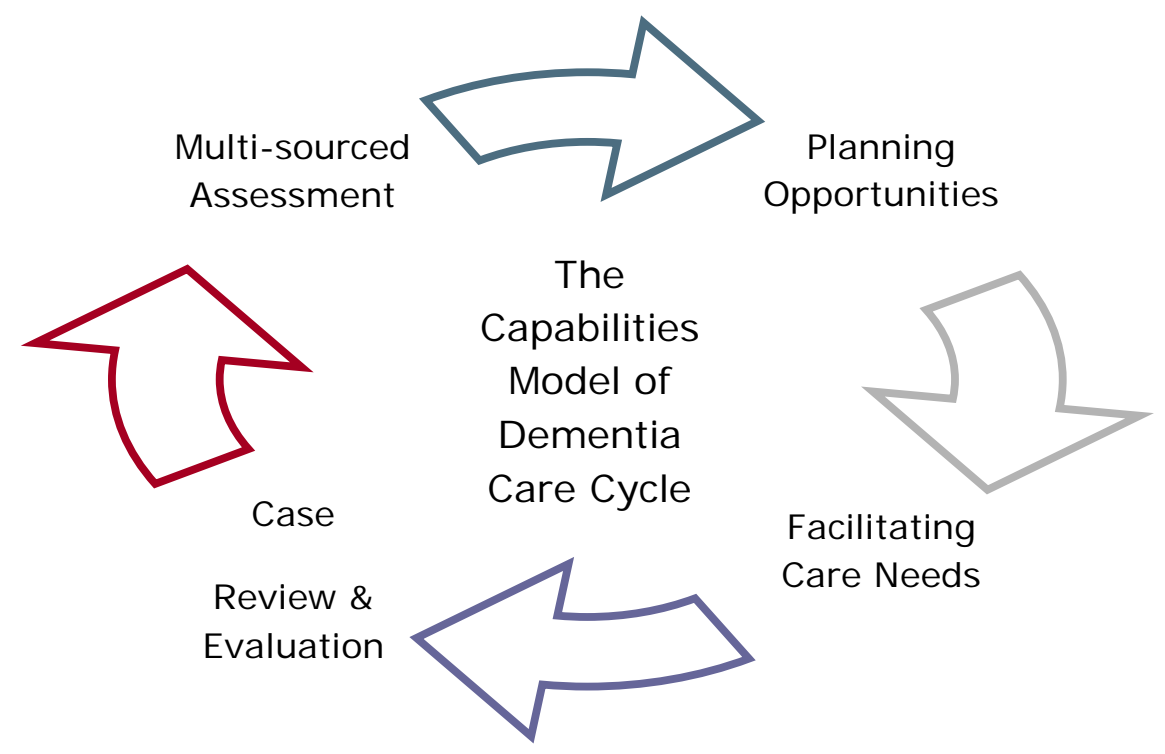

Figure 1: The capabilities model of dementia care cycle 